\title{
Article \\ Influence of Fluid Compressibility and Movements of the Swash Plate Axis of Rotation on the Volumetric Efficiency of Axial Piston Pumps
}

Paweł Załuski (D)

check for updates

Citation: Załuski, P. Influence of Fluid Compressibility and Movements of the Swash Plate Axis of Rotation on the Volumetric Efficiency of Axial Piston Pumps. Energies 2022, 15, 298. https:// doi.org/10.3390/en15010298

Academic Editor: Wencheng Guo

Received: 24 November 2021

Accepted: 31 December 2021

Published: 2 January 2022

Publisher's Note: MDPI stays neutral with regard to jurisdictional claims in published maps and institutional affiliations.

Copyright: (c) 2022 by the author. Licensee MDPI, Basel, Switzerland. This article is an open access article distributed under the terms and conditions of the Creative Commons Attribution (CC BY) license (https:// creativecommons.org/licenses/by/ $4.0 /)$.
Faculty of Mechanical Engineering and Ship Technology, Gdansk University of Technology, 80-233 Gdansk, Poland; pawel.zaluski@pg.edu.pl

\begin{abstract}
This paper describes the design of a swash plate axial piston pump and the theoretical models describing the bulk modulus of aerated and non-aerated fluids. The dead space volume is defined and the influence of this volume and the fluid compressibility on the volumetric efficiency of the pump is considered. A displacement of the swash plate rotation axis is proposed to reduce the dead space volume for small swash plate swing angles. A prototype design of a pump with a displaced axis of rotation of a swash plate with two directions of delivery is presented, in which the capacity is changed by means of a valve follow-up mechanism. Comparative results for a pump with a displaced and a non-displaced swash plate rotation axis are presented, which confirm that displacement of the swash plate rotation axis causes an increase in volumetric efficiency that is apparent for high pressure discharge and small swash plate angles. The determined characteristics were compared with a mathematical model taking into account the compressibility of the fluid in the dead space volume and a satisfactory consistency was obtained.
\end{abstract}

Keywords: hydraulic pump; axial piston pump; volumetric efficiency; fluid bulk modulus

\section{Introduction}

The history of axial piston pumps begins with Cooper and Hampton's 1893 design [1], which was revised and put into production by Williams and Janney 10 years later. Since then, the design and parameters of these pumps have changed considerably, but the principle of operation shown in Figure 1 has remained the same. The shaft (1) of the pump is connected with the drum (2) in which pistons (4) are located in cylinder chambers, in which slippers (5) are in contact with the swash plate (6). Due to the contact of the slippers with the swash plate, the pistons make reciprocating movements in the cylinder chambers of the drum during rotation. The front surface of the rotating drum (2) is in contact with the stationary timing plate (3), which has two kidney-shaped holes. One of these openings is connected to the suction channel (9), the other to the pump discharge channel (8). The cylinder chambers, from which the pistons extend, are thus connected by means of a timing plate to the suction channel and the fluid is sucked in. When the shaft continues to rotate and the pistons pass the dead point, they begin to approach the timing plate-the cylinder chambers are then connected to the delivery channel and fluid is pressed out of them. The axial piston hydraulic pumps with swash plate described in [2-5] are generally used in technology. The efficiency of axial piston pumps depends on the swing angle of swash plate and is zero for a swash plate which is vertical to the shaft axis. For pumps with two delivery directions, the swash plate is swinging in both directions.

The flow rate generated by the pump is pulsed due to the unpaired number of pistons and their variable speed [6]. This phenomenon is also influenced by other factors such as the inertia of the fluid and the swash plate profile and control method described in [7-10]. The torque acting on the swash plate, coming from the piston slippers, is also pulsating nature, methods for its calculation are described in [11-15]. Many works have been dedicated 
to the piston-cylinder kinematic pair. A description of the lubricating film formation between the contoured piston and the cylinder can be found in [16]. The influence of grooves on the piston on the conditions of hydrodynamic lubrication is described in [17]. Hydrodynamic lubrication is also written about in [18]. In the article [19] friction forces occurring at this joint were measured. The phenomena accompanying the hydrostatic support under the slipper are widely described [20]. In [21] a lubricating wedge formed under the piston slipper is described. A CFD analysis of the influence of the grooves in the slipper on the pressure distribution is carried out in [22]. In [23], a leakage analysis under the slipper for a piston equipped with a screw throttle can be found. The timing is responsible for the greater part of the losses in piston pumps. Therefore, work has been done to understand the phenomena occurring there, and to optimise the cylinder-timing plate pair. The dynamic phenomena accompanying drum loading [24] and leakage in the cylinder drum-timing plate joint [25] are studied. An evaluation of power losses in this joint has also been made [26]. In [27] computer analyses of the node are carried out using the CASPAR program, in [28] a comparison of theoretical models can be found, as well as research and optimisation of the drum-timing plate pair. Reference [29] describes the influence of relief grooves on the operating conditions at this location.

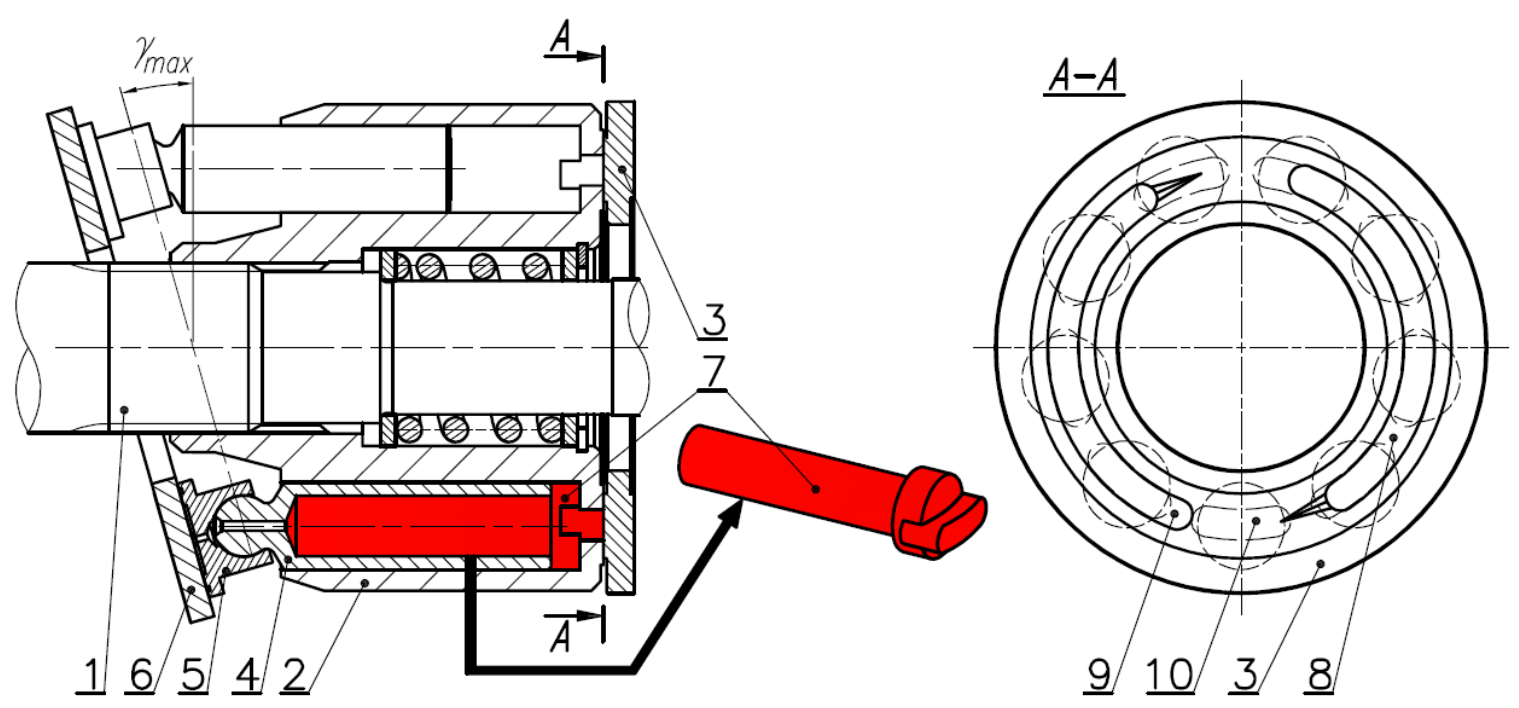

Figure 1. Working mechanism of axial piston pump: 1-shaft; 2-cylinder drum; 3-timing plate; 4-piston; 5-slipper; 6-swash plate; 7-dead space volume; 8-delivery channel; 9-suction channel; 10-timing bridge.

Axial piston pumps have a frontal timing device with a positive overlap, usually with relief grooves. The shape and flow through these grooves and the phenomena occurring in the flow through the valve bores are described in articles [30-32]. The volumetric efficiency of these pumps is influenced by leakage, the compressibility of the working fluid and the deformability of the working chambers [33]. For working pressures up to $20 \mathrm{MPa}$ and for a non-aerated working fluid, a volumetric efficiency model considering only leakage can be used [34]. At high delivery pressures and with large relative dead space volumes occurring for small swash plate swing angles, the compressibility of the working fluid has a significant effect on the volumetric efficiency [35]. In the case of a non-aerated liquid, the determination of the fluid bulk modulus does not present problems [36], but such a liquid is not encountered in real applications. There are many models describing the value of the modulus $K$ as a function of the aeration $X_{0}$ [37]. They can be divided according to the way of describing the process of compression of an aerated liquid. The first group of models includes the ideal gas equation in its description, assuming that the mass of air in the gas phase remains constant during the compression process. This group includes the Merrit, Nykanen and Cho-Feldman models. The second group of models also takes into account 
the gas state equation, but also takes into account the partial or complete dissolution of air in the oil as the pressure increases. This group includes the Yu and Ruan-Burton models. The Yu model is a development of the Cho model, which has been supplemented with a definition of Henry's law defining the solubility of a gas in a liquid valid up to $30 \mathrm{MPa}$. In this relation, Yu introduced the bubble size differentiation coefficient $c_{1}$, the value of which was determined experimentally according to the description given in [38]. The Ruan-Burton model also assumes dissolution of air in oil, but does not require determining its factors by experimental methods, which makes it possible to apply without testing. The model assumes that the air dissolves in the oil until the pressure reaches the critical value $p_{c}$ equal to $3.7 \mathrm{MPa}$ for dry air. Above the critical pressure, all air is assumed to have dissolved in the oil and the gas phase is assumed to have disappeared. For this reason, it is assumed that the further course of the bulk modulus variation corresponds to the course of the $K$ modulus for un-aerated oil. The Ruan-Burton model as well as the very similar LMS model are discontinuous models. This causes a step change in the modulus value in the $p_{c}$ pressure region, which makes these models difficult to apply. Gholizadeh [39] modified the LMS model to get rid of the discontinuity of the function at this location.

Research on positive displacement pumps is now mostly concentrating on reducing noise [40], optimising the design of individual components [41,42] increasing efficiency [43] and reducing the pulsation of the generated flow [44]. In all commercially available axial piston pumps, the axis of rotation of the swash plate intersects with the axis of rotation of the drive shaft. This solution is advantageous in terms of the load on the capacity change mechanism. Moments of forces acting from the piston slippers on the swash plate mutually balance each other and in order to override the swash plate a torque that is not large in relation to the forces acting on the swash plate is required. However, this solution has a serious drawback-as the swing angle of the swash plate decreases, the volume of dead space increases. The oil accumulated in this space expands into the suction channel causing reverse flow and limiting the volumetric efficiency of such pumps. The effect of this phenomenon on the volumetric efficiency is particularly evident for high discharge pressures and small swash plate swing angles [32,36]. Thus, displacement of the axis of rotation of the swash plate will result in an increase in the volumetric efficiency of the pump, visible for small swing angles of swash plate. So far, this phenomenon has been considered theoretically, and research has been conducted in a limited range on specially developed prototypes without industrial application [45]. The obtained results provided an impulse to create a new design of pump that could be applied in closed and open loop industrial hydraulic systems.

\section{Materials and Methods}

Figure 1 shows the dead space volume in red, i.e., the volume occupied by the working fluid in the cut-off cylinder chamber when the piston is in its extreme position at the end of the pressing phase. This space consists of the part of the cylinder, the cylinder barrel window and the empty space inside the piston. The empty space inside the piston represents a significant part of the dead space volume. The use of a solid piston results in a significant reduction of the dead space volume and thus an increase in volumetric efficiency, but at the same time this results in the increasing pump noise and flow ripple. The higher mass of the piston increases the inertia forces transmitted through the joint.

The displacement volume of one cylinder chamber of the pump is a function of the swash plate swing angle:

$$
V_{s}=\frac{\pi d_{t}^{2}}{4} \cdot D \cdot \tan (\gamma)
$$

Comparing the dead space volume to the stroke volume gives the relative dead space volume [30]:

$$
\varepsilon_{D}=\frac{V_{D}}{V_{S}}
$$


Currently series-produced axial piston pumps have one thing in common-the axis of rotation of the swash plate intersects with the axis of rotation of the shaft, which causes the dead space volume to increase when the swing angle of the swash plate is decreased (Figure 2).
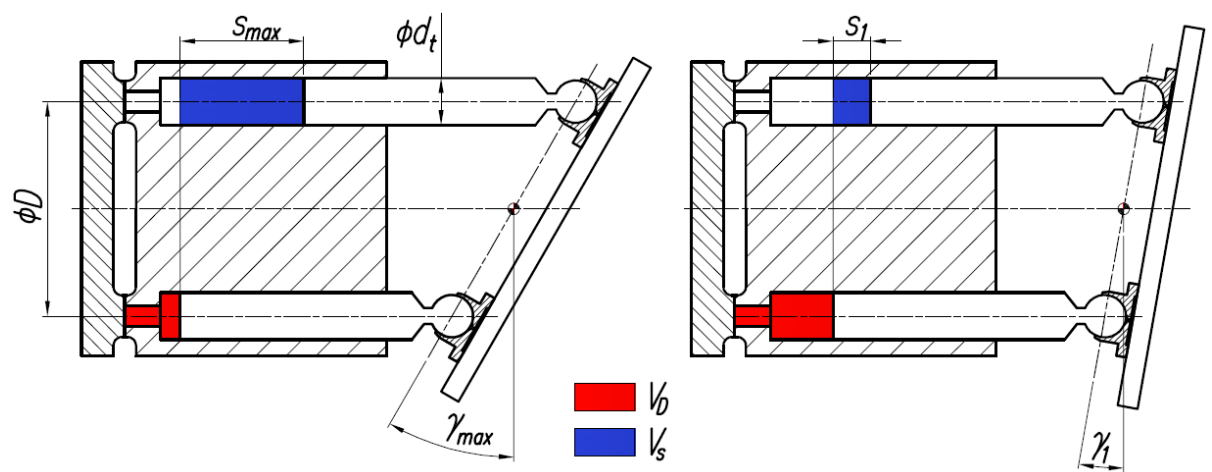

Figure 2. Relationship between swash plate swing angle $\gamma$, stroke volume $V_{S}$ and dead space volume $V_{D}$.

If the axis of rotation of the swash plate intersects with the axis of rotation of the shaft, as in Figure 2, then for angle $\gamma_{\max }$ the dead space volume is minimal and increases with decreasing swash plate angle $\gamma$ according to the following relation: if the swash volume decreases by $\Delta V$, the dead space volume increases by $\Delta V / 2$ :

$$
V_{D}=V_{D \min }+\frac{\pi d_{t}^{2}}{8} \cdot D \cdot\left[\tan \left(\gamma_{\max }\right)-\tan (\gamma)\right]
$$

The relative volume of the dead space depending on the swing angle of swash plate will be:

$$
\varepsilon_{D}=\frac{V_{D}}{V_{s}}=\frac{4 \cdot V_{D \min }}{\pi \cdot d_{t}^{2} \cdot D \cdot \tan (\gamma)}+\frac{1}{2}\left(\frac{\tan \left(\gamma_{\max }\right)}{\tan (\gamma)}-1\right)
$$

\subsection{Compressibility of the Working Fluid}

As the pressure increases, the volume of the working fluid decreases. The compression and expansion of the oil in the working chambers of the pump occurs at a high speed and can therefore be regarded as an isentropic phenomenon. The fluid volume changes are described by the isentropic compressibility factor:

$$
\beta_{S}=-\frac{1}{V} \cdot\left(\frac{\partial V}{\partial p}\right)_{S}
$$

Its inverse is the isentropic bulk modulus $K_{S}$. With a non-linear course of fluid volume change as a function of pressure, the bulk modulus can be determined as tangent or secant (Figure 3). The tangent modulus will be:

$$
K_{S}^{T}=-V\left(\frac{\partial p}{\partial V}\right)=\frac{-V}{\tan \alpha_{T}}
$$

In contrast, the secant module:

$$
K_{S}^{S}=-V\left(\frac{\Delta p}{\Delta V}\right)=\frac{-V}{\tan \alpha_{S}}
$$




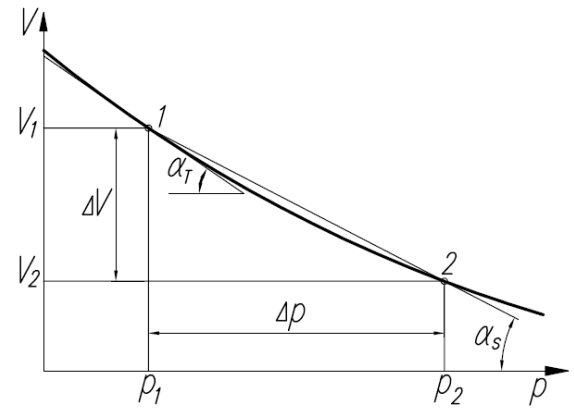

Figure 3. Method of determining the tangential and secant bulk modulus.

For mineral oils an approximate value for the bulk modulus can be determined from an empirical relationship [45]:

$$
K_{S}=\left[(1.62+0.15 \cdot \log v) \cdot 10^{(0.0028(20-t))}\right] 10^{3}+11.5 \cdot p
$$

where:

$K_{S}$-isentropic tangential bulk modulus [MPa],

$\mathrm{N}$-kinematic viscosity at atmospheric pressure and temperature $40^{\circ} \mathrm{C}\left[\mathrm{mm}^{2} / \mathrm{s}\right], t$-working fluid temperature $\left[{ }^{\circ} \mathrm{C}\right]$ and $p$-working fluid pressure [MPa].

\subsection{Compressibility of the Aerated Working Fluid}

In hydraulic systems, the working fluid is always aerated to a certain extent. The amount of air dissolved in the oil at a given pressure is determined by Henry's law. This law states that at a constant temperature, the volume of gas dissolved in the fluid is directly proportional to the pressure. Air dissolved in oil does not affect its elastic properties. A mixture of oil with air bubbles, however, has a much lower bulk modulus than an unaerated oil. When the pressure is decreased, air will be released from the solution in the form of bubbles, but when the pressure is increased, the air bubbles will enter back into solution with the oil. This means that the bulk modulus of the aerated oil is constantly changing, depending mainly on the pressure change. The effective bulk modulus of hydraulic aerated fluids is a function of the specific fluid, the entrained air content of the fluid, and the operating pressure and temperature of the fluid. The degree of aeration of oil $X_{0}$ can be described as [39]:

$$
X_{0}=\frac{V_{G}}{V_{G}+V_{C}}
$$

where $V_{G}$ is the volume of air at NTP conditions and $V_{C}$ is the volume of oil at NTP conditions. In the literature, several models are known to describe the bulk modulus of aerated oil. The simplest of them take into account the equation of state of ideal gas, assuming that the mass of air in the gas phase remains constant during the compression process. Among them, there can be distinguished the Cho model, which is a transformation of the Feldman model [39]:

$$
K_{C h o}=\frac{\left(1-X_{0}\right)+\left(\frac{p_{0}}{p}\right)^{\frac{1}{n}} X_{0}}{\frac{X_{0}}{n \cdot p}\left(\frac{p_{0}}{p}\right)^{\frac{1}{n}}+\frac{1-X_{0}}{K}}
$$

where:

$p_{0}$-atmospheric pressure,

$p$-absolute pressure,

$K$-bulk modulus for non-aerated oil and

$n$-polytrope exponent. 
Another model is the one proposed by the author which is a modified Feldman relation [46]:

$$
K_{\text {Feld mod }}=\frac{\left[1+\frac{m\left(p-p_{0}\right)}{K_{0}}\right]^{-\frac{1}{m} e^{\left(\frac{p_{0}-p}{K_{0}}\right)}+\frac{X_{0}}{\left(1-X_{0}\right)}\left(\frac{p_{0}}{p}\right)^{\frac{1}{n}}}}{\left[1+\frac{m\left(p-p_{0}\right)}{K_{0}}\right]^{-\frac{m+1}{m}}\left[\frac{e^{\left(\frac{p_{0}-p}{K_{0}}\right)}}{K_{0}}\right]+\frac{X_{0}}{n p_{0}\left(1-X_{0}\right)}\left(\frac{p_{0}}{p}\right)^{\frac{1+n}{n}}}
$$

where:

$m$-coefficient taking into account the influence of pressure on the increase of the modulus $K(p)=K+m p$ and $K_{0}$-tangent bulk modulus of non-aerated oil at atmospheric pressure.

The second group of models is also based on the ideal gas equation of state, but takes into account the dissolution of air in the oil as the pressure increases according to Henry's law. Among these models, the Yu model can be distinguished:

$$
K_{Y u}=\frac{K\left[X_{0}\left(\frac{p_{0}}{p}\right)^{\frac{1}{n}}+\left(1+X_{0}\right)\right]}{1-X_{0}+X_{0}\left(\frac{p_{0}}{p}\right)^{\frac{1}{n}}\left\{1+\left[1+c_{1}\left(p-p_{0}\right)\right]\left(\frac{K}{n \cdot p}-1\right)\right\}}
$$

The coefficient $c_{1}$ determines the air bubble diversity, its value was experimentally determined in [34]. Substituting the value of $c_{1}=-9.307 \times 10^{-6}$ given in [39] into the Yu model, the Yu model coincides with the Cho model. The second model taking into account the dissolution of air in oil is the Ruan and Burton model. This model assumes that air dissolves in oil until the pressure reaches a critical value $p_{c}$ equal to $3.7 \mathrm{MPa}$ for dry air. Above the critical pressure it is assumed that all air has dissolved in the oil and the gas phase has disappeared:

$$
K_{R-B}= \begin{cases}\frac{1+\left(\frac{p_{0}}{p}\right)^{\frac{1}{n}} \cdot \frac{X_{0}}{1-X_{0}} \cdot \frac{p_{c}-p}{p_{c}-p_{0}}}{\frac{1}{K}+\left(\frac{p_{0}}{p}\right)^{\frac{1}{n}} \cdot \frac{X_{0}}{1-X_{0}} \cdot \frac{1}{p_{c}-p_{0}} \cdot\left(\frac{p_{c}-p}{n \cdot p}+1\right)} & p \in\left(0, p_{c}\right\rangle \\ K & p \in\left(p_{c}, \infty\right)\end{cases}
$$

The disadvantage of the Ruan-Burton model is the discontinuity of the function and its step change around the pressure $p_{c}$. Figures $4-6$ compare the results obtained from the above models.

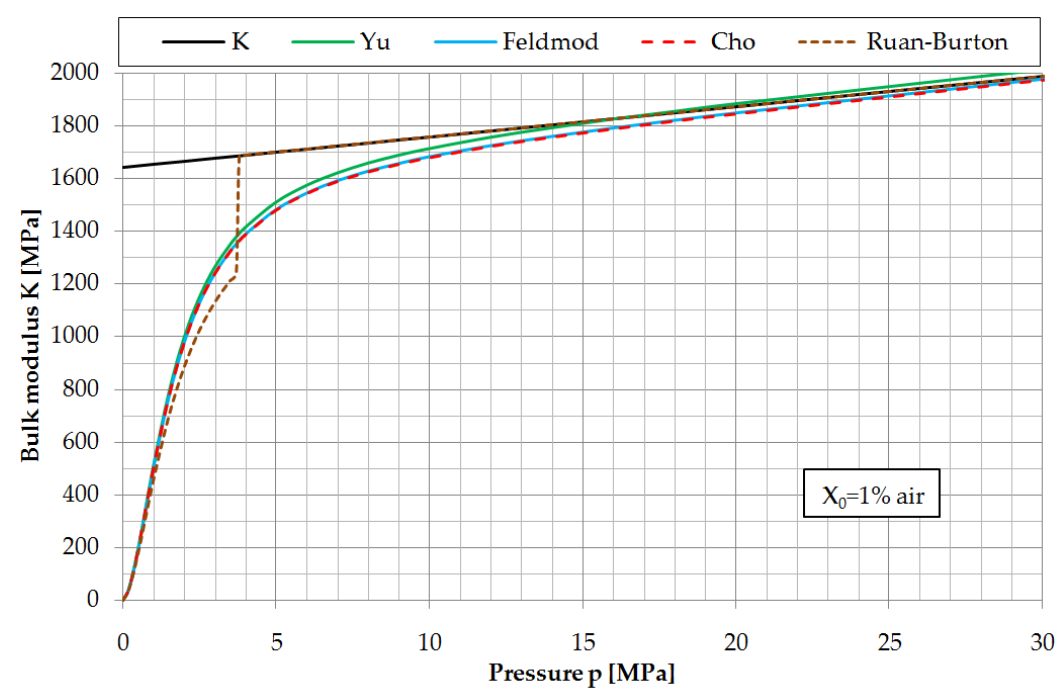

Figure 4. Comparison of models describing bulk modulus of aerated oil with modulus $K$ of nonaerated oil determined from relation (8) for $t=40^{\circ} \mathrm{C}, v=46 \mathrm{~mm}^{2} / \mathrm{s}, X_{0}=0.01$. 


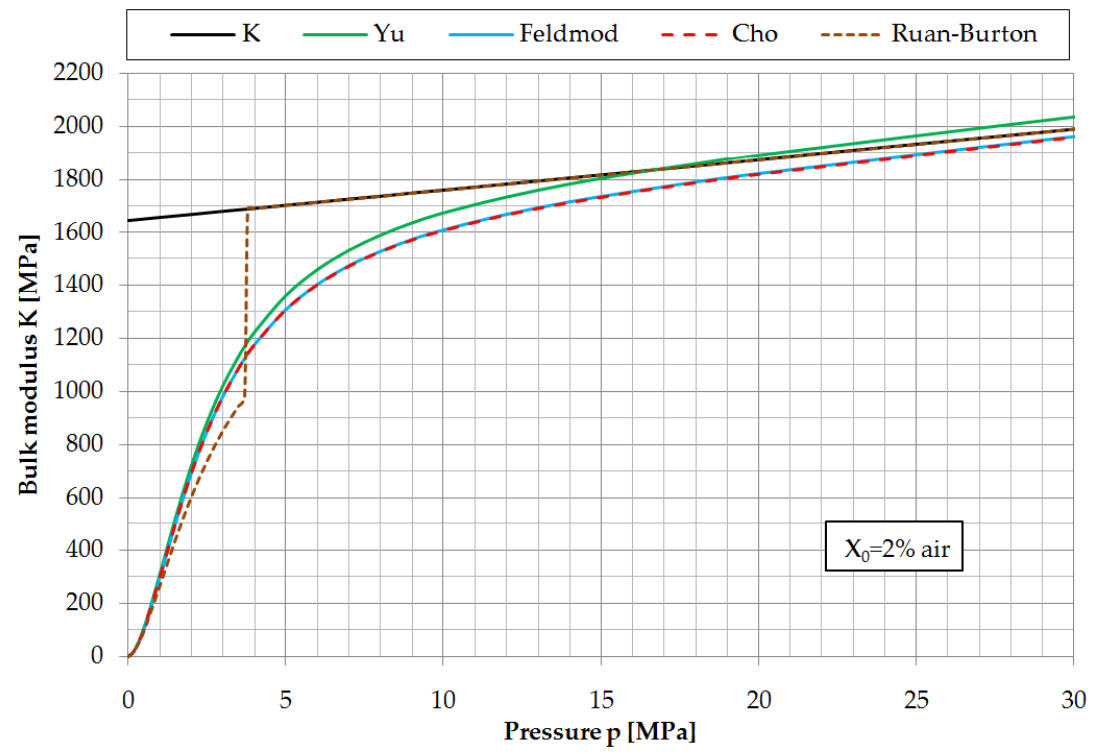

Figure 5. Comparison of models describing bulk modulus of aerated oil with modulus $K$ of nonaerated oil determined from relation (8) for $t=40{ }^{\circ} \mathrm{C}, v=46 \mathrm{~mm}^{2} / \mathrm{s}, X_{0}=0.02$.

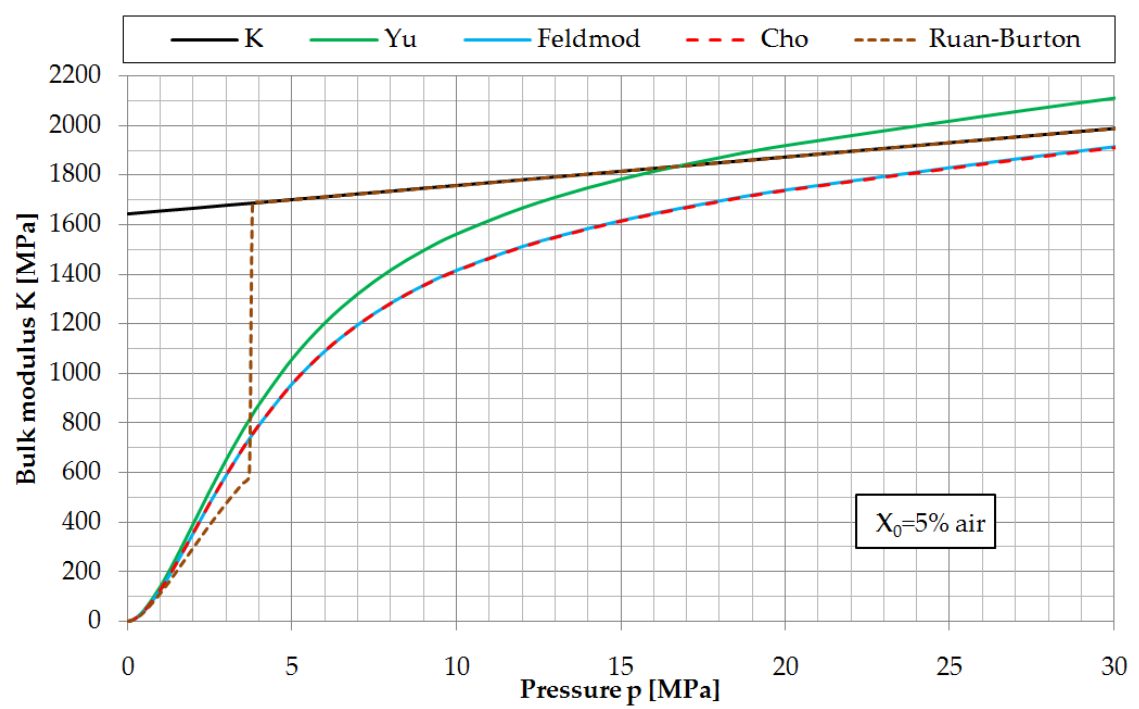

Figure 6. Comparison of models describing bulk modulus of aerated oil with modulus $K$ of nonaerated oil determined from relation (8) for $t=40{ }^{\circ} \mathrm{C}, v=46 \mathrm{~mm}^{2} / \mathrm{s}, X_{0}=0.05$.

The discontinuity of the functions from the Ruan-Burton model makes it difficult to apply this model in further considerations. As it can be seen, the results obtained from the modified Feldman and Cho models coincide with each other. Both these models have satisfactory convergence with the results of [45]. Due to the simpler mathematical notation, the Cho model will be used in further considerations.

\subsection{Influence of Fluid Compressibility on Volume Losses}

The operation of a positive displacement pump can be illustrated by the $p-v$ diagram shown in Figure 7. If the effect of the compressibility of the working fluid is ignored, during the suction phase the volume of the working chamber and the fluid filling will change from $V_{\min }$ to $V_{\max }$ at pressure $p_{0}$. Then the chamber enters the pressing phase and its volume is reduced from $V_{\max }$ to $V_{\min }$ under pressure $p_{1}$. This ideal course is marked in the figure with a dashed line. During real operation, due to the change in fluid volume under pressure, the shape of the circuit changes. During the pressing phase, when the 
volume of the working chamber changes from $V_{\max }=V_{B}$ to $V_{\min }=V_{D}$ the volume of the pressed fluid due to the reduction of its volume under pressure by $\Delta V_{1}=V_{B}-V_{C}$ will be only $V_{C}-V_{D}$. At the end of the pressing phase, a chamber with a volume $V_{\min }$ is cut off and filled with oil at a pressure $p_{1}$. The volume $V_{\min }$ corresponds to the dead space volume. At the transition to the suction phase, the working fluid accumulated in the dead space expands by $\Delta V_{C}=V_{A}-V_{D}$ causing a backflow into the suction channel and thus reducing the amount of liquid actually sucked in. If the axis of rotation of the swash plate intersects with the axis of rotation of the drive shaft, decreasing the swing angle of the swash plate decreases the stroke volume while increasing the dead space volume. This results in a stronger effect of liquid expansion on relative volume losses.

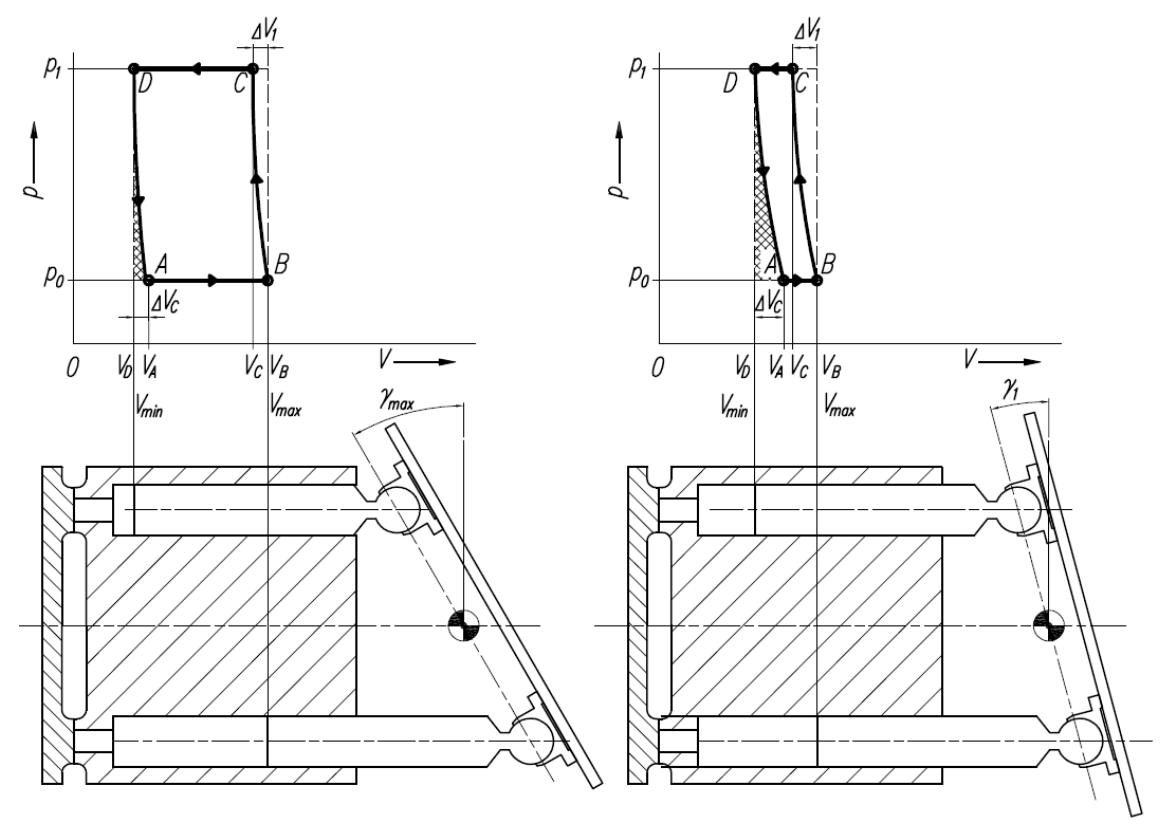

Figure 7. The $p-v$ diagram showing the operation of a positive displacement pump taking into account the compressibility of the working fluid.

The change in volume of the expanded oil can be described as [35]:

$$
\Delta V_{c}=\left(\Delta V_{c}+V_{\text {min }}\right) \frac{\Delta p}{K_{S}}=\left(\Delta V_{c}+V_{D}\right) \frac{\Delta p}{K_{S}}
$$

Due to the fact that the phenomenon of expansion of the liquid from pressure $p_{1}$ to $p_{0}$ is of the adiabatic character, the secant isentropic bulk modulus $K_{S}$ should be used to describe it. After the transformation:

$$
\Delta V_{c}=V_{D} \cdot \frac{\Delta p}{K_{S}^{S}-\Delta p}
$$

Determining the volume of the dead space from the swing angle of swash plate $\gamma$ obtained:

$$
\Delta V_{c}=\left[V_{D \text { min }}+\frac{\pi d_{t}^{2}}{8} \cdot D \cdot\left(\tan \left(\gamma_{\max }\right)-\tan (\gamma)\right)\right] \cdot \frac{\Delta p}{K_{S}^{S}-\Delta p}
$$

The flow rate losses can be defined as:

$$
\Delta Q_{s}=\Delta V_{c} \cdot n_{r} \cdot z
$$

where:

$n_{r}$-pump shaft speed and $z$-number of pistons. 
When the working fluid is expanded into the suction collector window, a volume $\Delta V_{c}$ is again sucked into the cylinder chamber, thus reducing the amount of new fluid sucked from the suction collector and affecting the apparent reduction in stroke volume. The effect of this phenomenon on relative volume loss can be described as:

$$
\Delta Q_{s w}=\frac{\Delta Q_{s}}{Q_{t}}=\frac{\Delta V_{c}}{V_{s}}
$$

As a result, the relative volume losses due only to compression of the fluid in the dead space will be:

$$
\Delta Q_{s w}=\left[\frac{4 \cdot V_{D \min }}{\pi \cdot d_{t}^{2} \cdot D \cdot \tan (\gamma)}+\frac{1}{2}\left(\frac{\tan \left(\gamma_{\max }\right)}{\tan (\gamma)}-1\right)\right] \frac{\Delta p}{K_{S}^{S}-\Delta p}
$$

The swing angle of swash plate $\gamma$ for which the relative volume losses are 1 can be determined from (19) as:

$$
\gamma_{\left(\Delta Q_{s w}=1\right)}=\arctan \left[\frac{\Delta p}{2 K_{S}^{S}-\Delta p}\left(\frac{8 V_{D \min }}{\pi \cdot d_{t}^{2} \cdot D}+\tan \left(\gamma_{\max }\right)\right)\right]
$$

The course of relative volume losses for pressures $\Delta p=5,10,20$ and $40 \mathrm{MPa}$ for a pump with $d_{t}=15.17 \mathrm{~mm}, D=67 \mathrm{~mm}, V_{D \min }=3.244 \mathrm{~cm}^{3}$ and $\gamma_{\max }=20.15^{\circ}$, and for a secant isentropic volume strain modulus $K_{S S}=1700 \mathrm{MPa}$ is shown in Figure 8.

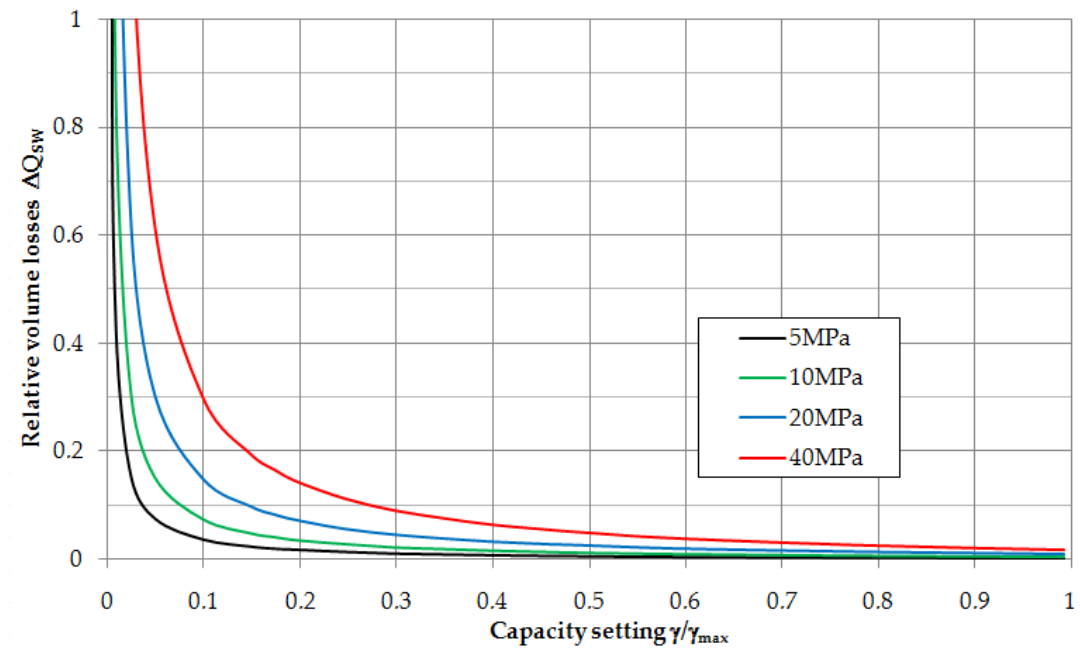

Figure 8. Relative volume losses in a function of capacity setting for pressures 5-40 MPa.

Figure 9 shows a situation where the axis of rotation of the swash plate is displaced from its original position by $a_{x}$ and $a_{y}$. The boundary condition is such a position of the swash plate at its maximum swing angle that the minimum dead space volume $V_{D \min }$ is obtained. In this way, regardless of the position of the axis of rotation of the swash plate, its position at the maximum swing angle will be the same. Consider the situation of a swash plate rotation with respect to a displaced centre of rotation from angle $\gamma_{\max }$ to angle $\gamma$ in a coordinate system with centre at the place where the centre of rotation of the swash plate was originally located. The plane of centres of the piston hinges is parallel to the plane of the swash plate along which the piston slipper move. It is therefore possible to analyse the displacement of the projection of this plane in a plane coordinate system as a function of the swing angle of swash plate. For the maximum swivel angle of the swash plate, the projection of this plane can be described by the equation of a straight line [45]:

$$
y=\frac{x}{\operatorname{tg} \gamma_{\max }} \operatorname{lub} \frac{1}{\operatorname{tg} \gamma_{\max }} x-y=0
$$




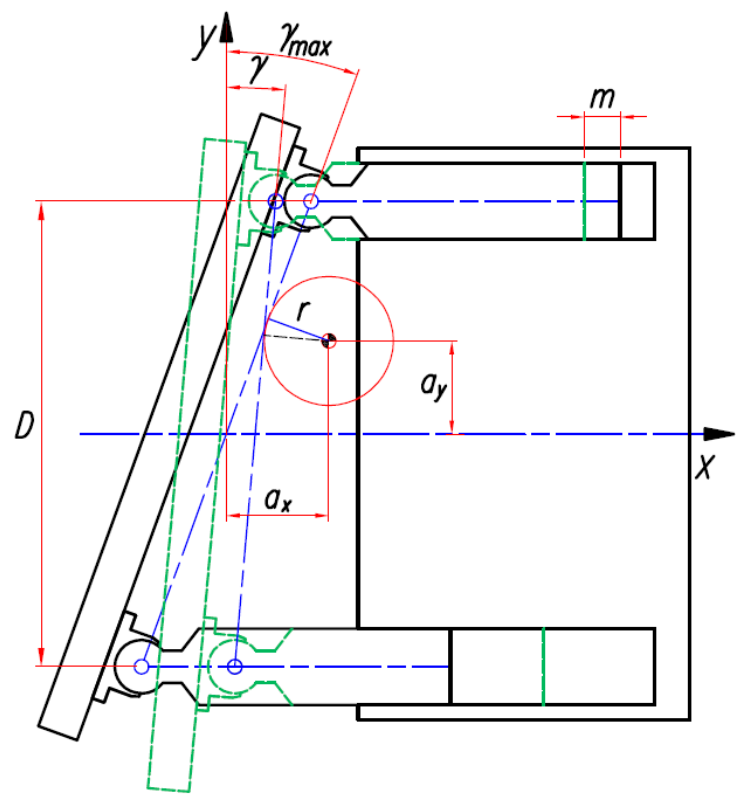

Figure 9. Displacement of the axis of rotation of the swash plate by $a_{x}$ and $a_{y}$ in relation to the axis of rotation intersecting with the shaft.

The radius of the circle in Figure 9 can be found as the shortest distance between its centre and the straight line representing the position of the centre plane of the piston hinges [45]:

$$
r=\frac{\left|\frac{a_{x}}{\operatorname{tg} \gamma_{\max }}-a_{y}\right|}{\sqrt{\frac{1}{\operatorname{tg}^{2} \gamma_{\max }}+1}}
$$

When the swash plate is rotated about its new centre of rotation to an angle $\gamma$, the straight line representing the projection of the plane of the piston hinges will also rotate by this angle, being tangent to the above circle all the time, so the equation can be derived:

$$
r=\frac{\left|\frac{a_{x}}{t g \gamma_{\max }}-a_{y}\right|}{\sqrt{\frac{1}{t^{2} \gamma_{\max }}}+1}=\frac{\left|\frac{a_{x}}{t g \gamma}-a_{y}-C\right|}{\sqrt{\frac{1}{\operatorname{tg}^{2} \gamma}+1}}
$$

After solving the above equation, we obtain two values of $C$, which are the points of intersection of the $y$-axis by tangents to the circle:

$$
\begin{aligned}
& \text { for } a_{x} \geq a_{y} \operatorname{tg} \gamma_{\max } \quad C=C_{1}=\frac{\left|\frac{a_{x}}{\operatorname{tg} \gamma_{\max }}-a_{y}\right| \sqrt{\frac{1}{\operatorname{tg}^{2} \gamma}+1}}{\sqrt{\frac{1}{\operatorname{tg}^{2} \gamma_{\max }}+1}}-\frac{a_{x}}{\operatorname{tg} \gamma}+a_{y} \\
& \text { for } a_{x} \leq a_{y} \operatorname{tg} \gamma_{\text {max }} \quad C=C_{2}=-\frac{\left|\frac{a_{x}}{\operatorname{tg} \gamma_{\max }}-a_{y}\right| \sqrt{\frac{1}{\operatorname{tg}^{2} \gamma}+1}}{\sqrt{\frac{1}{\operatorname{tg}^{2} \gamma_{\max }}+1}}-\frac{a_{x}}{\operatorname{tg} \gamma}+a_{y}
\end{aligned}
$$

The volume of the dead space which is a function of the position of the centre of rotation and the swing angle of the swash plate can be described as:

$$
V_{D}=V_{D \min }+\frac{\pi d_{t}^{2}}{4}\left[\frac{D}{2} \operatorname{tg} \gamma_{\max }-\left(\frac{D}{2}-C\right) \operatorname{tg} \gamma\right]=V_{D \min }+\frac{\pi d_{t}^{2}}{4} m
$$

An image of changes in the dead space volume (without $V_{D \min }$ ) as a function of the position of the swash plate rotation axis is the plane shown in Figure 10. As it can be 
seen, the dead space volume changes significantly with a displacement of the centre of rotation along the $y$-axis (i.e., perpendicular to the shaft axis). However, moving the centre of rotation upwards from the shaft axis has the positive effect of reducing the dead space volume in comparison with the conventional solution.

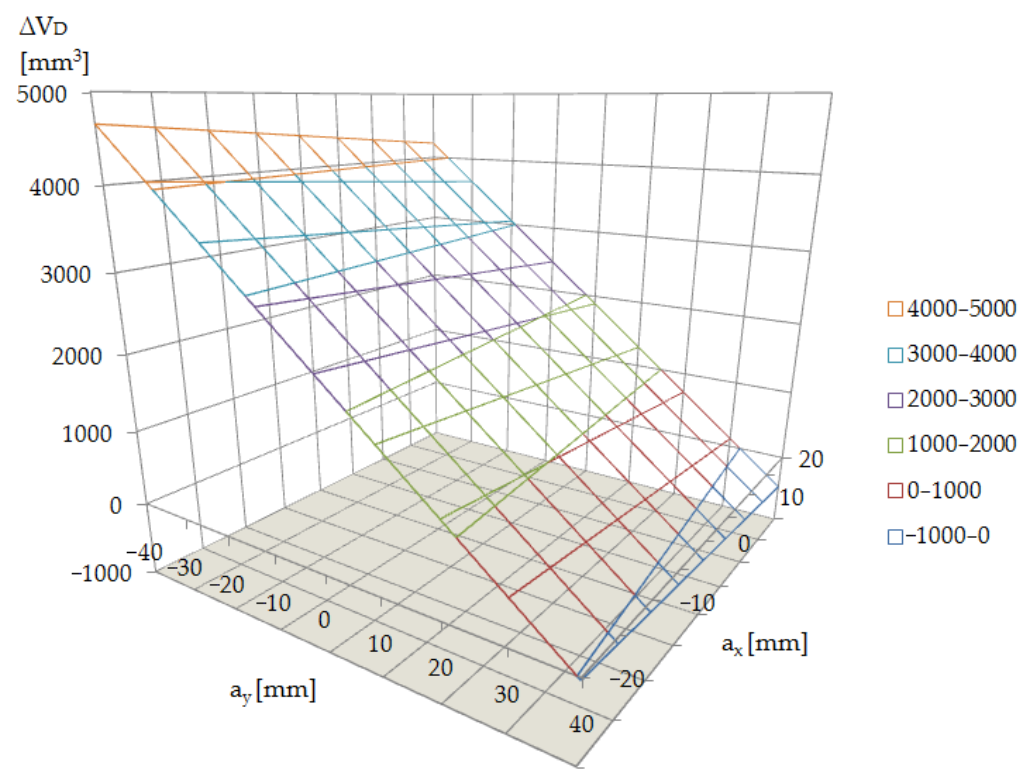

Figure 10. Change in dead space volume as a function of the position of swash plate rotation axis for a pump with $D=67 \mathrm{~mm}, d_{t}=15.17 \mathrm{~mm}, \gamma=1^{\circ}, \Delta V_{D}$-change in dead space volume.

If the axis of rotation of the swash plate is moved as in Figure 11, then regardless of the angle of the swash plate, the volume of this space will be constant and will be $V_{D m i n}$.
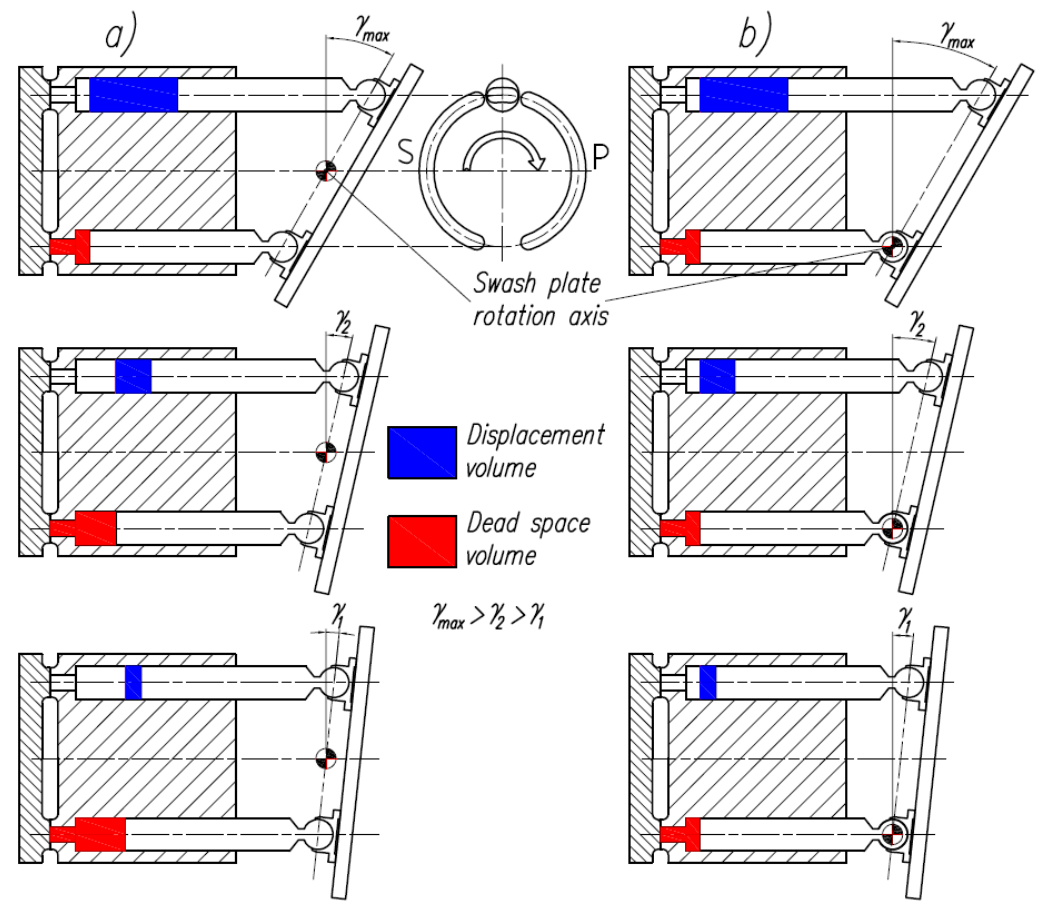

Figure 11. Comparison of the changing dead space volume as a function of swash plate swing angle for a pump with swash plate rotation axis intersecting with shaft rotation axis (a) and a pump with displaced swash plate rotation axis (b). 
Therefore, Equation (19) describing the relative volume losses due to fluid compressibility will take the form:

$$
\Delta Q_{s w}=\left[\frac{4 \cdot V_{D \min }}{\pi \cdot d_{t}^{2} \cdot D \cdot \tan (\gamma)}\right] \frac{\Delta p}{K_{S}^{S}-\Delta p}
$$

A comparison of relative volume losses for pressures $\Delta p=20$ and $40 \mathrm{MPa}$ for a pump with displaced and non-displaced swash plate axis of rotation of $d_{t}=15.17 \mathrm{~mm}, D=67 \mathrm{~mm}$, $V_{\text {Dmin }}=3.244 \mathrm{~cm}^{3}$ and $\gamma_{\max }=20.15^{\circ}$, and for secant isentropic bulk modulus $K_{S S}=1700 \mathrm{MPa}$ is shown in Figure 12.

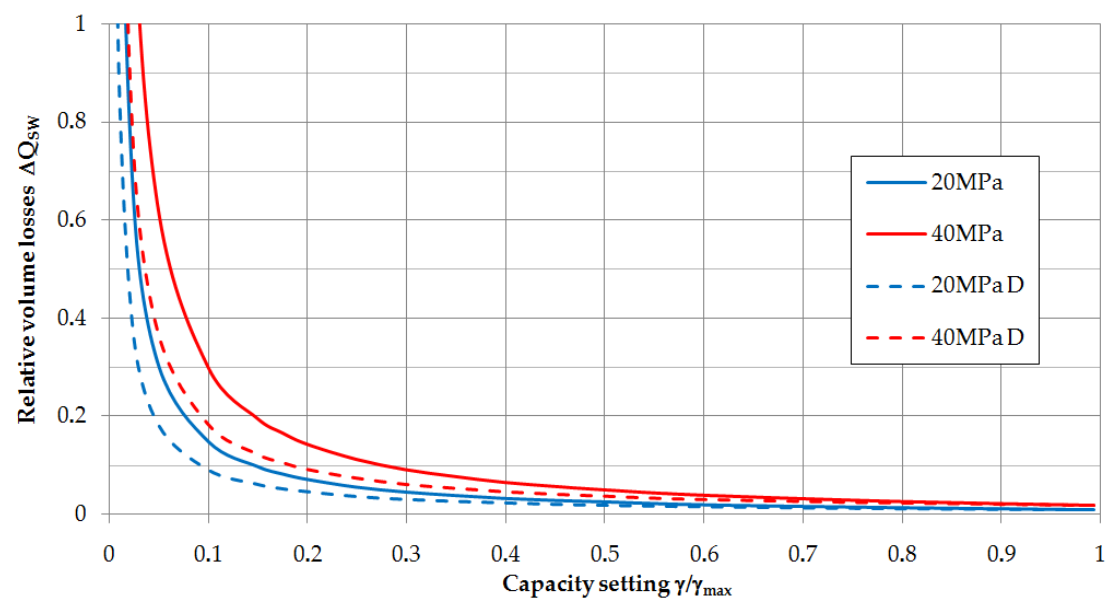

Figure 12. Relative volume losses due to compression of the fluid in the dead space as a function of pump capacity setting, for a pump with swash plate rotation axis intersecting with shaft rotation axis and displaced axis (D) for $q=40 \mathrm{~cm}^{3} / \mathrm{rev}$.

\section{Experimental Research}

The pump shown in Figure 13 is a prototype construction with twin pumping directions in which the axis of rotation of the swash plate is displaced so that the dead space volume is constant when the swash plate angle changes. The swash plate (10) is supported by movable supports (5) located in the housing (6). The supports (5) are rotatable and their tips contact a suitably formed raceway made in the disc (10). The tip of the support (12) is also the axis of rotation of the swash plate. The drive shaft (1) is connected with the drum (2), in which there are pistons (4) ended with slippers (13). The slippers slide on the swash plate (10), the piston stroke, and thus the pump capacity, depends on the swing angle of the swash plate. The rotating drum (2) contacts the fixed timing plate (3). The swash plate (10) is connected to the piston (11) of the capacity change cylinder $(7 \mathrm{a}, \mathrm{b})$ by means of a pin (8) and connectors (9). In Figure 13a the swing angle of the swash plate is changed by the actuator (7a). To change the direction of pumping, the pump capacity must be reduced to zero by extending the piston (11). When the swash plate (10) is perpendicular to the axis of the shaft (1), the supports (5) are rotated to the position shown in Figure 13b. Now the swing angle of the swash plate is set by the actuator $(7 \mathrm{~b})$.

A scheme of the test stand is shown in Figure 14. The test pump (1) was pre-supplied by the backing pump (2). The suction pressure was regulated by the relief valve (5), and the delivery pressure by the relief valve (6). During the tests, the pressures before and after the pump, the oil temperature in the suction port, the flow rate, the torque and the speed were measured. The working fluid was mineral oil class VG 46. The temperature stabilisation system composed of an oil-water cooler (9) and a heater set (10) was responsible for maintaining a constant oil temperature during the tests. Leakage from the pump housing was drained to the measuring cylinder (18), and from there, by means of the filter unit (3), back to the tank (19). The view of the test stand is shown in Figure 15. 


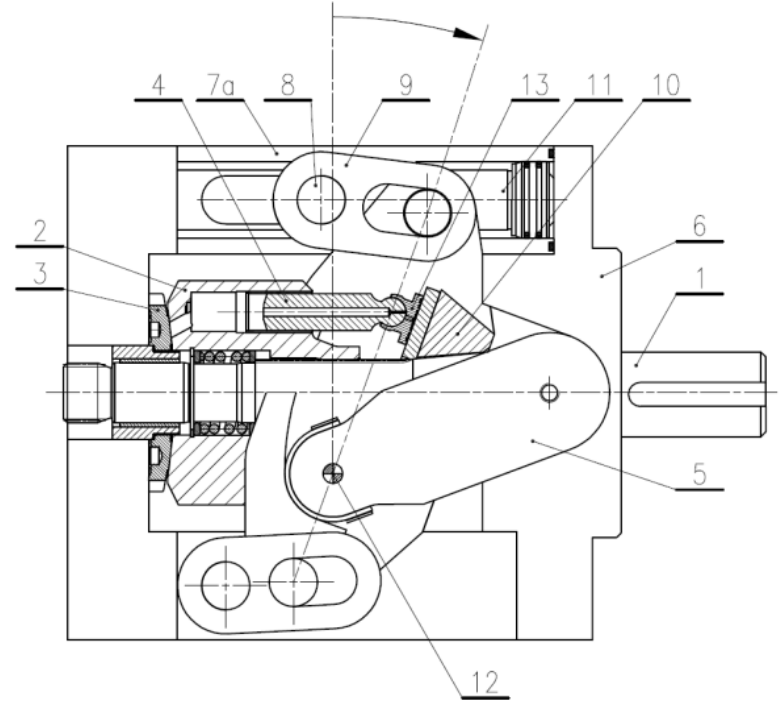

(a)

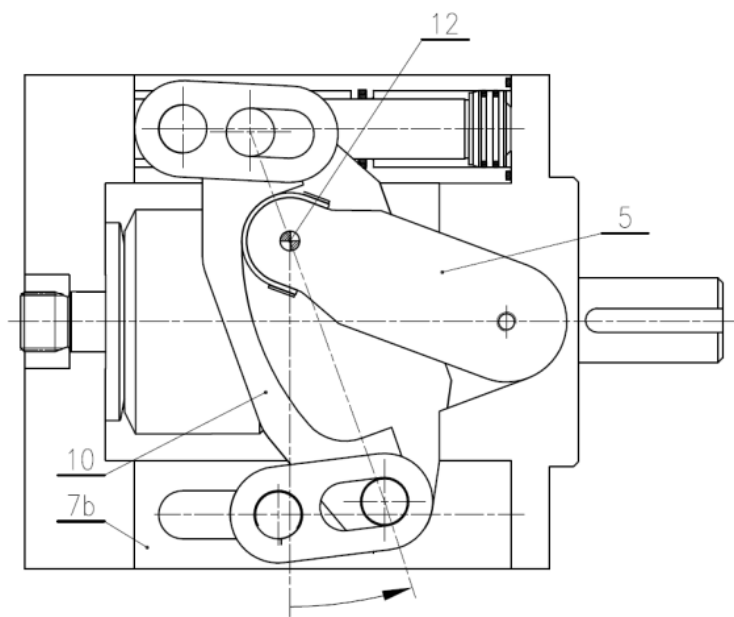

(b)

Figure 13. Design of a prototype pump with two pumping directions with a displaced axis of rotation of the swash plate: (a) pump pumping in one direction; (b) pump pumping in the opposite direction; 1-shaft; 2-cylinder drum; 3-timing plate; 4-piston; 5-swash plate support; 6-housing; 7a, 7b-displacement actuators; 8-pin; 9-connector; 10-swash plate; 11-rod; 12-tip of support (swash plate axis of rotation); 13-slipper.

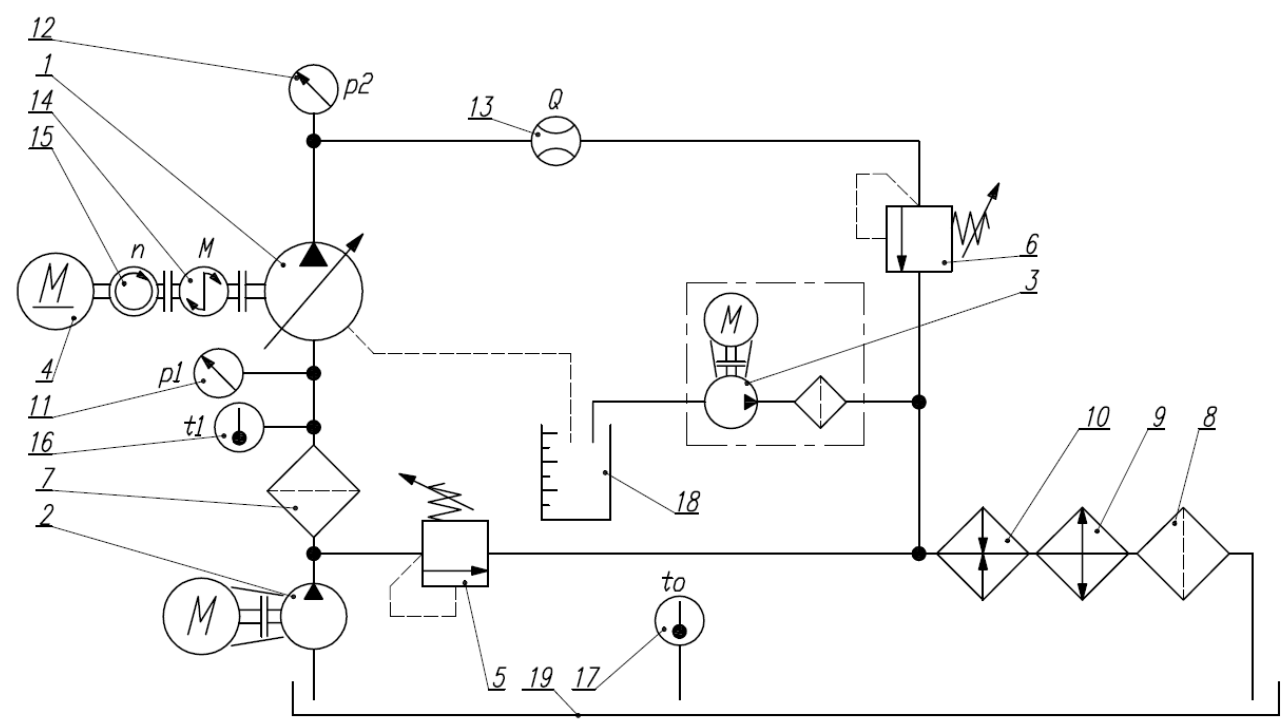

Figure 14. Test stand scheme: 1-test pump; 2-backing screw pump; 3-filter unit; 4-DC electric motor $70 \mathrm{~kW}$; 5-suction pressure control relief valve; 6-relief valve 0-40 MPa; 7, 8-oil filters; 9-cooler; 10 electric heaters $12 \times 1.6 \mathrm{~kW} ; 11$,12-pressure gauges; 13-piston flow meter PT-200; 14-torque transducer HBM T1 500 Nm; 15-optical speed sensor; 16, 17-temperature transducers; 18-leakage measuring cylinder; 19-oil tank 1700 L. 


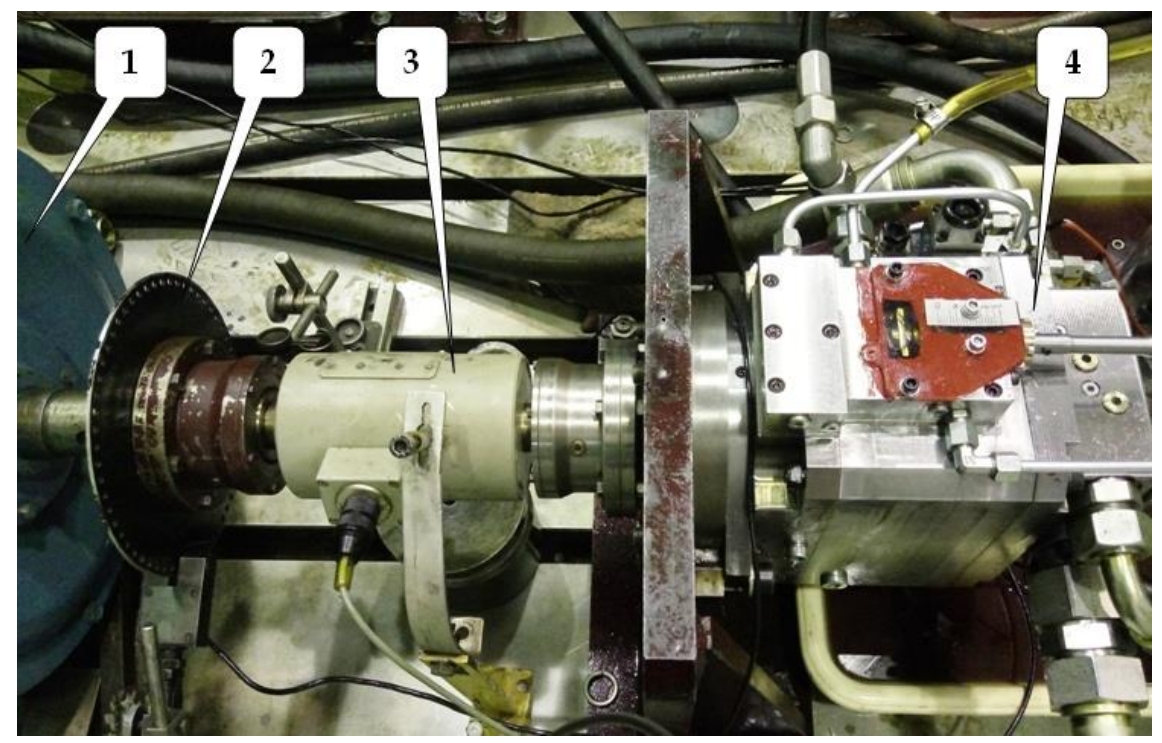

Figure 15. View of the test stand: 1-electric motor; 2-speed sensor; 3-torque meter; 4-tested pump.

The main parameters of the tested pump are listed in Table 1.

Table 1. Main parameters of tested pump.

\begin{tabular}{ccc}
\hline Parameter & Value & Unit \\
\hline Displacement $q$ & 40 & $\mathrm{~cm}^{3} / \mathrm{rev}$ \\
Pistons spacing $D$ & 67 & $\mathrm{~mm}$ \\
Piston diameter $d_{t}$ & 15.17 & $\mathrm{~mm}$ \\
Number of pistons $z$ & 9 & - \\
Dead space volume $V_{D}$ & 3.244 & $\mathrm{~cm}^{3}$ \\
Max. swash plate swing angle $\gamma_{\max }$ & 20 & $\mathrm{deg}$ \\
Nominal pressure $p$ & 40 & $\mathrm{MPa}$ \\
\hline
\end{tabular}

At first, measurements were performed for a market pump with a displacement of $40 \mathrm{~cm}^{3} / \mathrm{rev}$. Then the working mechanism of this pump, i.e., a cylinder drum with pistons and a timing plate, was used to build a prototype pump. Using the same working mechanism in both designs should result in both designs having similar leakage, and any increase in efficiency will be due to a reduction of the dead space volume. The tests were carried out at a constant speed and oil temperature. The discharge pressure was gradually increased up to $35 \mathrm{MPa}$ and the average flow rate generated by the pump was recorded, as well as the leakage rate from the pump housing. Tests were carried out at speeds between 500 and $2200 \mathrm{rpm}$. The test results of the prototype with the displaced axis of rotation of the swash plate and the tests carried out on the market pump with the same working mechanism are presented in Figure 16. The working displacement and the swash plate angle were determined on the basis of measurements from the characteristic curve $Q=f(p)$ for a constant speed of rotation. 


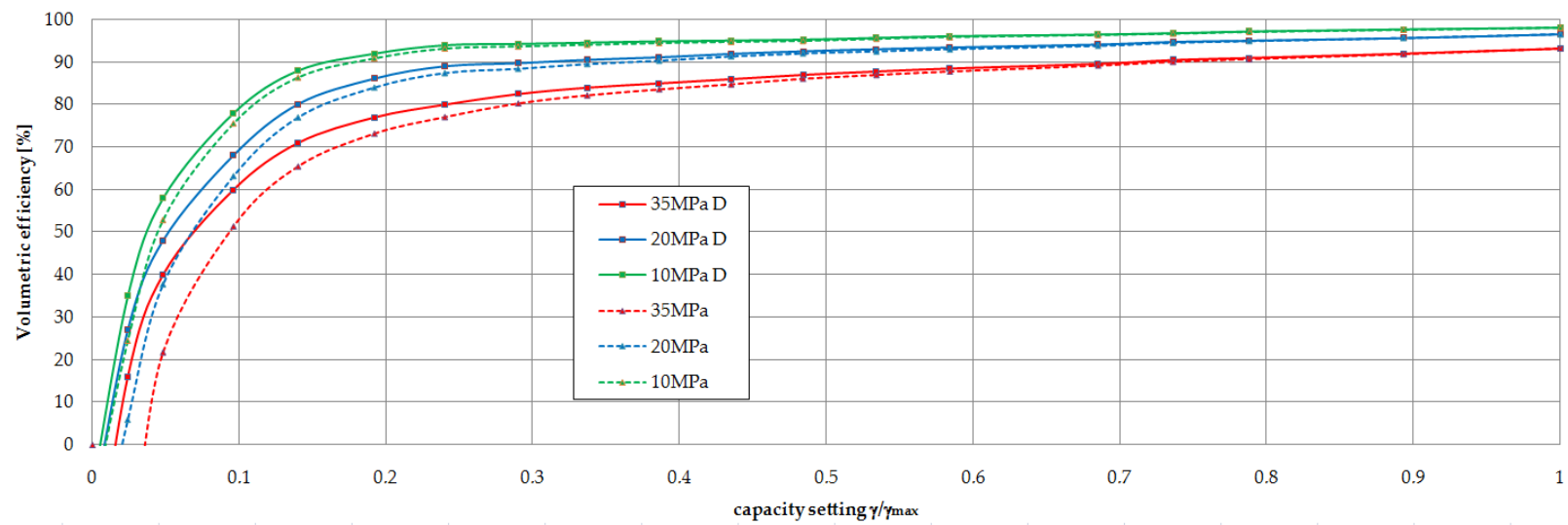

Figure 16. Comparison of volumetric efficiency for a pump with displaced and non-displaced axis of rotation of swash plate for $q=40 \mathrm{~cm}^{3} / \mathrm{rev}, 2000 \mathrm{rpm}, 40 \mathrm{~mm}^{2} / \mathrm{s}$.

The volumetric efficiency difference is already noticeable for delivery pressures from $10 \mathrm{MPa}$ and increases with increasing pressure. The improved volumetric efficiency is particularly visible at small pump capacity settings. The effect is noticeable up to settings for approximately $1 / 3$ of the full capacity of the pump. The changes in relative volumetric losses, i.e., volumetric losses related to the theoretical capacity for both pump designs are shown in Figure 17.

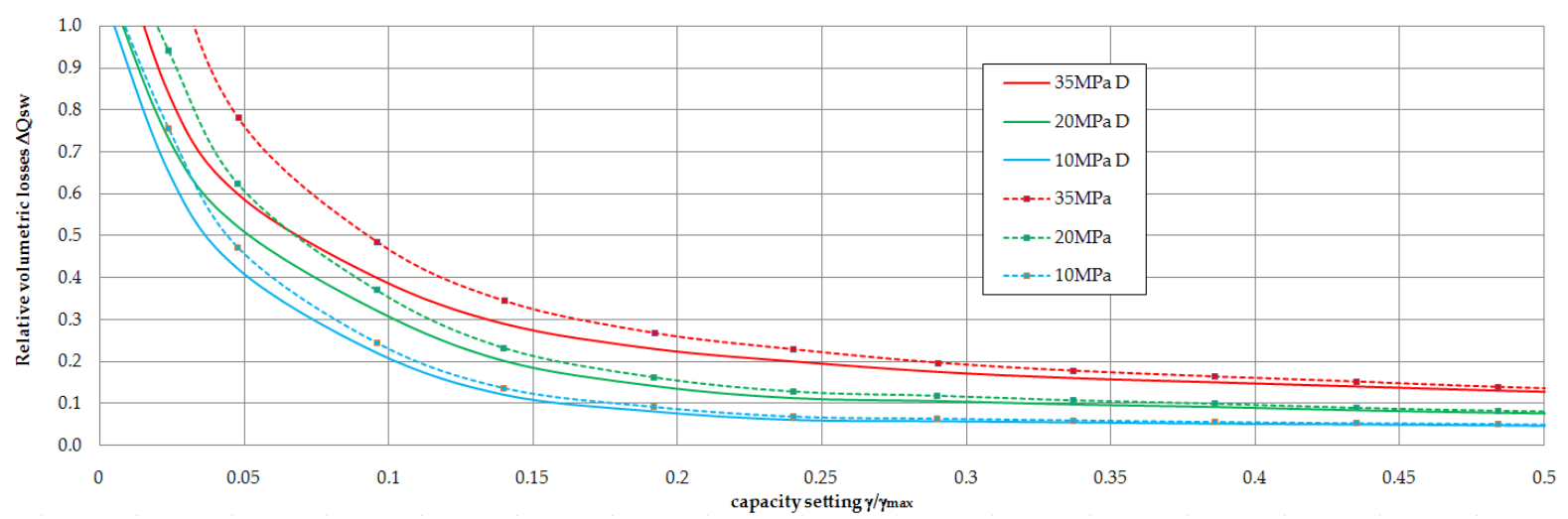

Figure 17. Comparison of the relative volumetric losses for a pump with the swash plate axis of rotation not displaced and displaced (D) for $q=40 \mathrm{~cm}^{3} / \mathrm{rev}, 2000 \mathrm{rpm}, 40 \mathrm{~mm}^{2} / \mathrm{s}$.

Again, there is a difference which consists in the reduction of the relative volumetric losses. If these losses are 1, the pump is not pumping liquid and the entire flow is internal leakage. It can be seen that for a delivery pressure of $35 \mathrm{MPa}$, the classic pump design starts pumping the fluid from a setting of 0.033 , i.e., a swash plate swing angle of $0.7^{\circ}$, while a pump with a displaced axis of rotation starts pumping the fluid from a setting of 0.015 , i.e., $0.35^{\circ}$. The difference between the relative volumetric losses between a displaced axis pump and a pump of classic design is shown in Figure 18. The results are compared with those obtained from a mathematical model based on relation (27). The model assumed that the same leakage would occur in both pumps. The model therefore only considered the effect of reducing the dead space volume. 


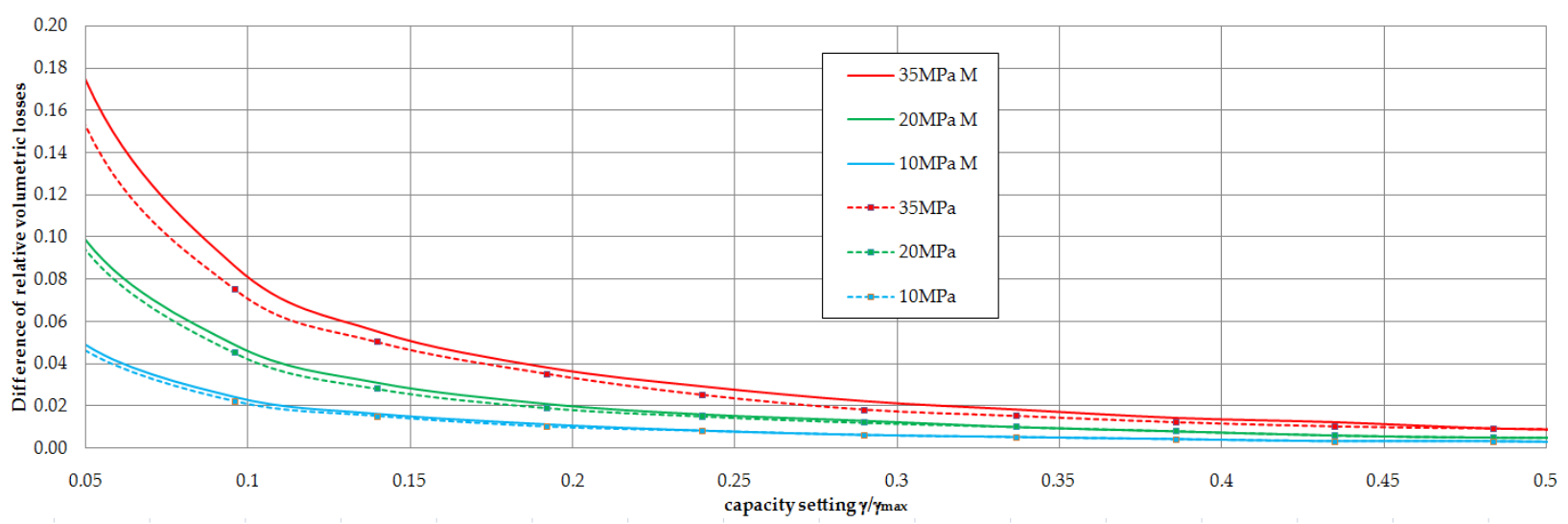

Figure 18. Difference of relative volumetric with displacement of swash plate rotation axis for a pump with $q=40 \mathrm{~cm}^{3} / \mathrm{rev}, 2000 \mathrm{rpm}, 40 \mathrm{~mm}^{2} / \mathrm{s}$. Solid line-model results, dashed line-test results.

The mathematical model assumed a bulk modulus of oil of $1838 \mathrm{MPa}+3.2 p$, where $p$ is the pressure in [MPa], giving a bulk modulus of $1950 \mathrm{MPa}$ for a pressure of $35 \mathrm{MPa}$. These values were adopted based on in-house compressibility tests of VG46 oil performed at the Laboratory of Hydraulics of the Gdansk University of Technology [36].

\section{Discussion and Conclusions}

The increase of volumetric efficiency when the swash plate rotation axis is displaced by $a_{y}=D / 2$ and $a_{x}=a_{y} \tan \gamma_{\max }$ is shown in Figure 19. The test results were compared there with a mathematical model based on relation (27), assuming the same leakages in both cases. The model therefore only considered the effect of dead space volume reduction. The volumetric efficiency is obtained by relating the relative volumetric losses to the theoretical capacity for a particular swing angle of the swash plate.

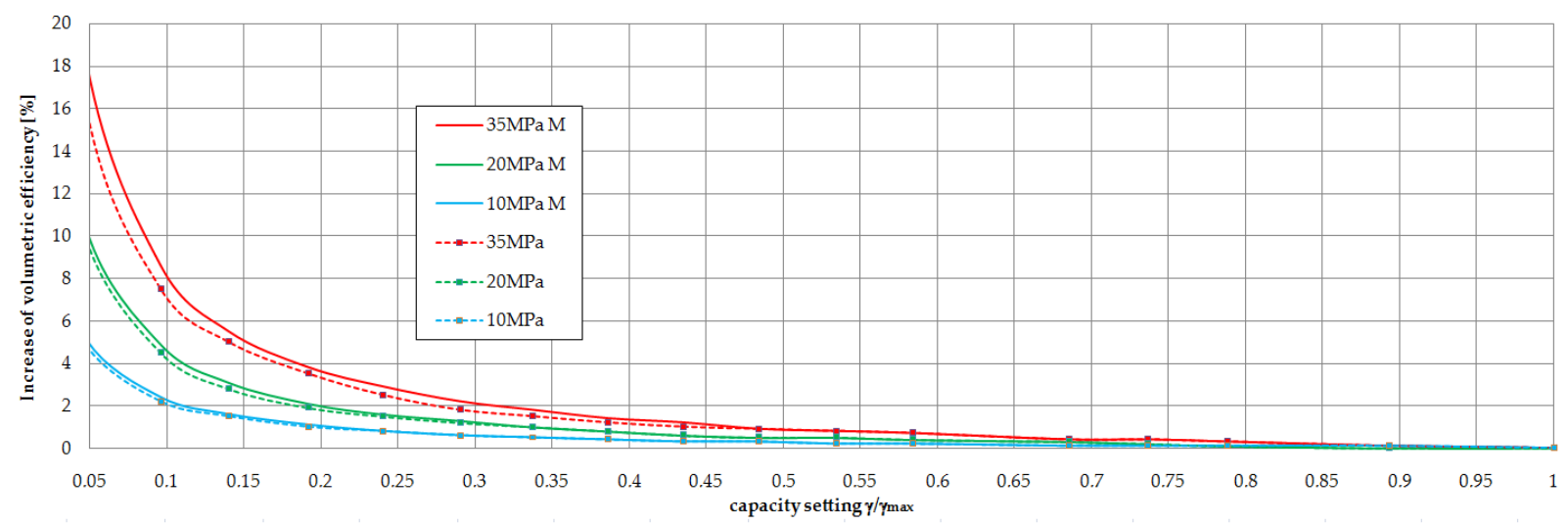

Figure 19. Increase of volumetric efficiency with displacement of swash plate rotation axis for a pump with $q=40 \mathrm{~cm}^{3} / \mathrm{rev}, 2000 \mathrm{rpm}, 40 \mathrm{~mm}^{2} / \mathrm{s}$. Solid line-model results, dashed line-test results.

The results obtained show that displacement of the axis of rotation of the swash plate results in a reduction of relative volume losses. This is particularly visible in Figure 17. For delivery pressure of $35 \mathrm{MPa}$ and a capacity setting of 0.05 , relative volumetric losses are reduced by up to about $15 \%$. Unfortunately, this effect is only visible at high delivery pressures (above $20 \mathrm{MPa}$ ) and at low capacity settings of the pump. However, this results in a proportional increase in the volumetric efficiency of the pump. The results obtained were compared with a simple mathematical model taking into account only the effect of fluid compressibility in the dead space. As a result, a satisfactory convergence of the results was obtained and the maximum error did not exceed $5 \%$. This confirms the assumption that the increase in volumetric efficiency is mainly due to dead space volume reduction. Of 
course, the model could be supplemented with at least a leakage analysis, but previous work [45] shows that leakage changes with swash plate rotation axis displacement are small and mainly concern leakage reduction in the piston-cylinder joint. The main problem appears to be determining the actual bulk modulus of oil, which depends on many factors such as temperature, pressure, rate of pressure change and degree of aeration. Therefore, the presented analysis is based on our own compressibility tests of oil. The conditions for these tests (closed measuring cylinder and slow increase of pressure) are different from the conditions in a closed cylinder chamber, so the determined value of modulus is only an approximation. The paper presents an innovative design of a prototype pump with a displaced swash plate rotation axis and two pumping directions. The development of this design posed many problems, because when changing the direction of discharge, the position of the axis of rotation of the swash plate should change. This was achieved by supporting the swash plate on rotating supports. The result is a pump in which the dead space volume is constant and independent of the swing angle of the swash plate. Displacement of the axis of rotation of the swash plate in the presented design results in unbalanced torques acting from the piston slippers on the swash plate. In effect, the forces required to overdrive the swash plate are many times greater than in conventional pump designs. This results in an increase in the pump overdrive time. The presented research data are the result of preliminary tests of the prototype. In the future, further tests of this prototype are planned, in particular tests of timing and flow ripple.

Funding: This research was funded by The National Centre for Research and Development within the framework of program LIDER, grant number: LIDER/22/0130/L-8/16/NCBR/2017. Project title: Hydro-mechanical automatic gearbox for agricultural vehicles and heavy machinery. Funding value: 1,197,500.00 PLN.

Institutional Review Board Statement: Not applicable.

Informed Consent Statement: Not applicable.

Data Availability Statement: The data presented in this study are openly available in [45]. Some of the data (prototype pump test results) are not publicly available as it is a part of the grant report. These data are available on request from the corresponding author.

Conflicts of Interest: The author declare no conflict of interest.

\section{References}

1. Cooper, W.; Hampton, G.P. Rotary Reciprocating Pump. U.S. Patent 511044, 19 December 1893.

2. Osiecki, A. Hydrostatyczny Napęd Maszyn; WNT: Warsaw, Poland, 1998.

3. Stryczek, S. Napęd Hydrostatyczny; PWN: Warsaw, Poland, 2005.

4. Ivantysynova, M. Hydrostatische Pumpen und Motoren. Konstruktion und Berechnung; Vogel: Wurzburg, Germany, 1993.

5. Cundiff, J.S. Fluid Power Circuits and Controls; CRC Press: Boca Raton, FL, USA, 2002.

6. Manring, N.D. The Discharge Flow Ripple of an Axial-Piston Swash-Plate Type Hydrostatic Pump. J. Dyn. Syst. Meas. Control 2000, 122, 263-268. [CrossRef]

7. Rundo, M.; Squarcini, R.; Furno, F. Modelling of a Variable Displacement Lubricating Pump with Air Dissolution Dynamics. SAE Int. J. Eng. 2018, 11, 111-126. [CrossRef]

8. Casoli, P.; Pastori, M.; Scolari, F.; Rundo, M. Active pressure ripple control in axial piston pumps through high-frequency swash plate oscillations-A theoretical analysis. Energies 2019, 12, 1377. [CrossRef]

9. Casoli, P.; Pastori, M.; Scolari, F. Swash plate design for pressure ripple reduction-A theoretical analysis. AIP Conf. Proc. 2019, 2191, 020038. [CrossRef]

10. Changbin, G.; Zongxia, J.; Shouzhan, H. Theoretical study of flow ripple for an aviation axial-piston pump with damping holes in the valve plate. Chin. J. Aeronaut. 2014, 27, 169-181.

11. Zeiger, G.; Akers, A. Torque on the Swashplate of an Axial Piston Pump. ASME J. Dyn. Syst. Meas. Control 1985, 107, 220-226. [CrossRef]

12. Schoenau, G.J.; Burton, R.T.; Kavanagh, G.P. Dynamic Analysis of a Variable Displacement Pump. ASME J. Dyn. Syst. Meas. Control 1990, 112, 122-132. [CrossRef]

13. Ericson, L. Swash Plate Oscillations due to Piston Forces in Variable In-line Pumps. In Proceedings of the 9th International Fluid Power Conference, Aachen, Germany, 24-26 March 2014. 
14. Manring, N.D.; Johnson, R.E. Modeling and Designing a Variable-Displacement Open-Loop Pump. J. Dyn. Syst. Meas. Control 1996, 118, 267-271. [CrossRef]

15. Norhirni, M.Z.; Hamdi, M.; Nurmaya Musa, S. Load and Stress Analysis for the Swash Plate of an Axial Piston Pump/Motor. J Dyn. Syst. Meas. Control 2011, 133, 064505. [CrossRef]

16. Gels, S.; Murrenhoff, H. Simulation of the lubricating film between contoured piston and cylinder. Int. J. Fluid Power 2010, 11, 15-24. [CrossRef]

17. Kumar, S.; Bergada, J.M. The effect of piston grooves performance in an axial piston pumps via CFD analysis. Int. J. Mech. Sci. 2013, 66, 168-179. [CrossRef]

18. Pelosi, M.; Ivantysynova, M. The impact of axial piston machines mechanical parts constraint conditions on the thermoelastohydrodynamic lubrication analysis of the fluid film interfaces. Int. J. Fluid Power 2013, 14, 35-51. [CrossRef]

19. Scharf, S.; Murrenhoff, H. Measurement of friction forces between piston and busching of an axial piston displacement unit. Int. J. Fluid Power 2005, 6, 7-17. [CrossRef]

20. Iboshi, N.; Yamaguchi, A. Characteristics of a Slipper Bearing for Swash Plate Type Axial Piston Pumps and Motors. 1st. Report, Theoretical Analysis. Bull. Jpn. Soc. Mech. Eng. 1982, 25, 1921-1930. [CrossRef]

21. Bergada, J.M.; Watton, J.; Haynes, J.M. The hydrostatic/hydrodynamic behavior of an axial piston pump slipper with multiple lands. Meccanica 2010, 45, 585-602. [CrossRef]

22. Kumar, S.; Bergada, J.M.; Watton, J. Axial piston pump grooved slipper analysis by CFD simulation of three-dimensional NVS equation in cylindrical coordinates. Comput. Fluids 2009, 38, 648-663. [CrossRef]

23. Patrosz, P. Influence of Gaps Geometry Change on Leakage Flow in Axial Piston Pumps. In Advances in Hydraulic and Pneumatic Drives and Control 2020. NSHP 2020; Lecture Notes in Mechanical Engineering; Stryczek, J., Warzyńska, U., Eds.; Springer: Berlin, Germany; pp. 76-89. [CrossRef]

24. Bergada, J.M.; Davies, D.; Xue, Y.; Kumar, S. Experimental Investigation in Axial Piston Pumps Barrel Dynamics. In Proceedings of the 10th International Conference on Fluid Control, Measurements, and Visualization FLUCOME 2009, Moscow, Russia, 17-21 August 2009.

25. Bergada, J.M.; Watton, J.; Kumar, S. Pressure, Flow, Force, and Torque Between the Barrel and Port Plate in an Axial Piston Pump. J. Dyn. Syst. Meas. Control 2008, 130, 011011. [CrossRef]

26. Ivantysynova, M.; Baker, J. Power loss in the lubricating gap between cylinder block and valve plate of swash plate type axial piston machines. Int. J. Fluid Power 2009, 10, 29-43. [CrossRef]

27. Wieczorek, U.; Ivantysynova, M. Computer aide optimization of bearing and sealing gaps in hydrostatic machines-The simulation tool CASPAR. Int. J. Fluid Power 2002, 3, 7-20. [CrossRef]

28. Zhao, J.; Fu, Y.; Ma, J.; Fu, J.; Chao, Q.; Wang, Y. Review of cylinder block/valve plate interface in axial piston pumps: Theoretical models, experimental investigations, and optimal design. Chin. J. Aeronaut. 2021, 34, 111-134. [CrossRef]

29. Złoto, T.; Sochacki, D. Impact of exploitation parameters on the hydrostatic relief of the cylinder block in an axial piston pump. Teka Com. Mot. Energ. Agric. 2012, 12, 263-268.

30. Cho, J.; Zhang, X.; Manring, N.D.; Nair, S. Dynamic modeling and parametric studies of an indexing valve plate pump. Int. J. Fluid Power 2002, 3, 37-48. [CrossRef]

31. Ma, J.; Fang, Y.; Xu, B.; Yang, H. Optimization of Cross Angle Based on the Pumping Dynamics Model. J. Zhejiang Univ.-Sci. A 2010, 11, 181-190. [CrossRef]

32. Osiecki, L. Mechanizmy Rozrzadu Hydraulicznych Maszyn Wielotłoczkowych Osiowych; Journal of Gdansk University of Technology: Gdańsk, Poland, 2006.

33. Śliwiński, P. The influence of water and mineral oil on volumetric losses in the displacement pump for offshore and marine applications. Pol. Marit. Res. 2019, 26, 173-182. [CrossRef]

34. Bergada, J.M.; Kumar, S.; Davies, D.L.; Watton, J. A complete analysis of axial piston pump leakage and output flow ripples. Appl. Math. Model. 2012, 36, 1731-1751. [CrossRef]

35. Osiecki, L. Wpływ przestrzeni martwej na straty energetyczne w pompach wielotłoczkowych. Hydraul. I Pneum. 2007, 27, 12-15.

36. Załuski, P. Experimental research of an axial piston pump with displaced swash plate axis of rotation. In Advances in Hydraulic and Pneumatic Drives and Control; Springer: Berlin, Germany, 2020; pp. 135-145. [CrossRef]

37. Patrosz, P. Influence of Properties of Hydraulic Fluid on Pressure Peaks in Axial Piston Pumps' Chambers. Energies 2021, 14, 3764. [CrossRef]

38. Yu, J.; Chen, Z.; Lu, Y. Variation of oil efective bulk modulus with pressure in hydraulic systems. J. Dyn. Syst. Meas. Control 1994, $116,146-150$.

39. Gholizadeh, H. Modeling and Experimental Evaluation of the Effective Bulk Modulus for a Mixture of Hydraulic Oil and Air. Ph.D. Dissertation, University of Saskatchewan, Saskatoon, SK, Canada, 2013.

40. Stosiak, M. The impact of hydraulic systems on the human being and the environment. J. Theor. Appl. Mech. 2015, 2, 409-420. [CrossRef]

41. Kollek, W.; Radziwanowska, U. Energetic efficiency of gear micropumps. Arch. Civ. Mech. Eng. 2015, 15, 109-115. [CrossRef]

42. Kollek, W.; Osiński, P.; Stosiak, M.; Wilczyński, A.; Cichoń, P. Problems relating to high-pressure gear micropumps. Arch. Civ. Mech. Eng. 2014, 14, 88-95. [CrossRef] 
43. Karpenko, M.; Bogdevičius, M. Review of energy-saving technologies in modern hydraulic drives. Civ. Transp. Eng. Aviat. Technol. 2017, 9, 553-558. [CrossRef]

44. Bury, P.; Osiński, P. Leakage location in high pressure external gear pump. In Proceedings of the 25th International Conference ENGINEERING MECHANICS 2019, Svratka, Czechia, 13-16 May 2019. [CrossRef]

45. Załuski, P. Influence of the Position of the Swash Plate Rotation Axis on the Volumetric Efficiency of Axial Piston Pumps. Ph.D. Dissertation, Gdansk University of Technology, Gdańsk, Poland, 2017. Available online: http:/ / mtmcongress.com/proceedngs / 2014/1/12.INFLUENCE\%20OF\%20THE\%20POSITION\%20OF\%20THE\%20SWASH\%20PLATE\%20ROTATION\%20AXIS\%20 ON\%20THE\%20VOLUMETRIC\%20EFFICIENCY\%200F\%20THE\%20AXIAL\%20PISTONS\%20PUMPS.pdf (accessed on 30 December 2021).

46. Śliwiński, P. Determination of the theoretical and actual working volume of a hydraulic motor. Energies 2020, 13, 5933. [CrossRef] 